\title{
Bioanalytical method by column-switching with direct injection of human plasma for determination of sulphonylureas
}

\author{
Juliana Veloso Ferreira, Gerson Antônio Pianetti, Christian Fernandes*
}

\author{
Department of Pharmaceutical Products, Faculty of Pharmacy, Federal University of Minas Gerais, Belo Horizonte, MG, Brazil.
}

*Corresponding author: cfernandes@farmacia.ufmg.br

Sulphonylureas are widely used in the treatment of Diabetes mellitus, one of the main causes of death in human population. Their determination is essential in pharmacological research and in the development of new drugs. Generally, determination of sulphonylureas in biological matrices is performed using conventional sample preparation techniques, which frequently leads to an increase of analysis time and errors. In this context, a bioanalytical method for the simultaneous determination of sulphonylureas by direct injection of human plasma was developed and optimized. An automated column-switching high performance liquid chromatographic system with a restricted access media (RAM) column coupled to a fused-core column was employed. At the first dimension, a RAM column with mobile phase of ultrapure water $\mathrm{pH} 6.0$ at a flow-rate of $1.0 \mathrm{~mL}$ min-1 was used. The valve switching time was 3 minutes. At the second dimension, a C18 guard-column coupled to a C18 fused core column

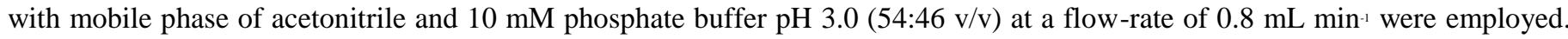
The column switching system was performed in backflush configuration with an analyte elution time of 1 minute. Flufenamic acid was used as the internal standard. The mean plasma protein exclusion percentage by the RAM-column was $104.5 \%$. The developed and optimized method showed to be fast and simple, allowing the direct injection of biological sample into the chromatographic system and the simultaneous determination of three sulphonylureas in only 12 minutes, including the sample treatment, separation and detection.

Keywords: sulphonylureas, column-switching, restricted access media, fused core column, human plasma.

\section{Introduction}

The analysis of drugs and metabolites in biological samples, mainly in plasma, is a common procedure for clinical diagnoses, toxicological analysis and pharmacological research. Recurrent problems found in bioanalysis are analytes low concentration, interferences due to the presence of other compounds and plasma proteins, and analyteprotein binding $(1,2)$.

When high-performance liquid chromatography (HPLC) is used for the analysis of biological matrices, a pre-treatment is necessary before the injection of the sample in the system. This procedure aims to concentrate the analyte and eliminate plasma proteins, since these macromolecules may suffer irreversible adsorption in the stationary phase of the analytical column, shortening its lifetime and increasing the system pressure. Therefore, the sample preparation is a critical and limiting step in the development of analytical methods for the determination of drugs in biological fluids by HPLC (1,3-5).

The sample preparation techniques may be classified in conventional and modern. Modern or miniaturized techniques are characterized by reduced analysis time and organic solvent consumption, as well as automation. Among the modern sample preparation techniques, online solid phase extraction (SPE) using restricted access media columns (RAM) deserve attention. This kind of support allows the direct injection of biological samples in the chromatographic system, because of its macromolecules exclusion mechanism, restraining their access to the support's adsorption sites $(6,7)$.

The direct injection of biological samples in the chromatographic system, through online mode, allows the reduction of the sample handling by the analyst, who will be less exposed to the sample and to toxic compounds. Also, the sample will be subject to less oxidation and evaporation, and the occurrence of error during the analysis will be lower. The automated mode employing RAM columns can be performed using a two-dimensional chromatographic system, controlled by a valve, with the extraction phase in the first dimension and the analytical step in the second dimension. First, the biological sample, usually plasma, is injected into the first dimension of the system and carried to the RAM column by the exclusion mobile phase (EMP), with the valve at position A. In the RAM column, the analytes are retained in the stationary phase and plasma protein excluded and discarded. After that, the automatic valve rotates to position $B$, and the analytical mobile phase (AMP) runs through the RAM column eluting the analytes into the analytical column, where separation occurs (Figure 1). In the backflush configuration, the AMP runs through the RAM column in an opposite flow direction of the EMP. Oppositely, in the foreflush configuration both AMP and EMP runs in the same direction through the RAM column (2,5,6,8-11).

Diabetes mellitus (DM) is one of the main causes of death in human population. It is estimated that DM affects the lives of about 382 millions of people in the world. It can be classified in type 1 - autoimmune disease in which a catabolic disturb leads to the absence of insulin, and type $2-$ heterogenic pathology encompassing many forms of diabetes, which have in common the insulin insufficiency or tissue insensitivity. Its treatment involves lifestyle change, maintenance of ideal weight and use of oral antidiabetic drugs, such as sulfonylureas. Figure 2 shows the chemical structure and some physical-chemical properties of the sulfonylureas analyzed in this study. These drugs are 
completely and rapidly absorbed by the gastrointestinal tract and are bound to plasma proteins, mainly albumin, by about 90-99\%. They are metabolized in the liver and their metabolites are excreted in urine (12-15).

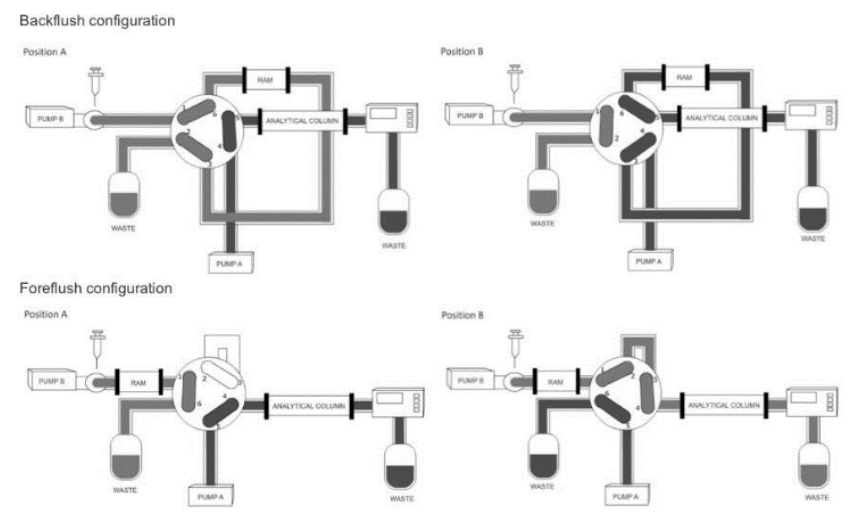

Figure 1. Backflush and foreflush configurations for the twodimensional chromatographic system.

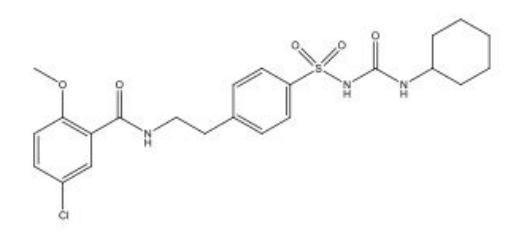

Glibenclamide (GB)
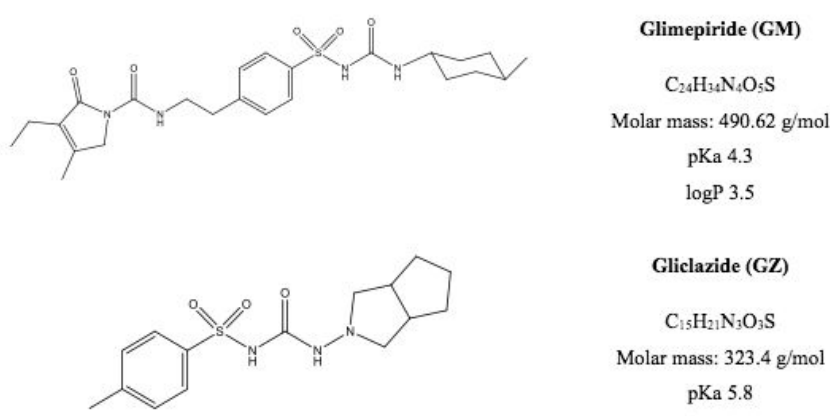

Gliclazide (GZ)

$\mathrm{C}_{15} \mathrm{H}_{21} \mathrm{~N}_{3} \mathrm{O}_{3} \mathrm{~S}$ Molar mass: $323.4 \mathrm{~g} / \mathrm{mol}$ pKa 5.8 $\log \mathrm{P} 2.6$

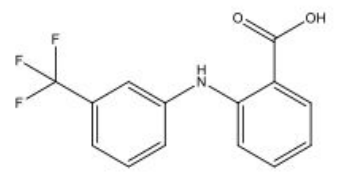

Flufenamic Acid (IS)

$\mathrm{C}_{14} \mathrm{H}_{10} \mathrm{~F}_{3} \mathrm{NO}_{2}$

Molar mass: $282.23 \mathrm{~g} / \mathrm{mol}$

pKa 3.88

$\log P 5.25$ presenting some advantages over conventional techniques, their main limitation is the lack of automation. One study was found describing the determination of glimepiride (GM) in plasma using column-switching with RAM column. The total time spent to determine only one sulfonylurea was 40 minutes (24).

In this context, the present study describes the optimization of a rapid and simple method, using a column-switching HPLC with RAM column (sample preparation) and fused core column (analytical separation), for the simultaneous determination of three sulfonylureas: glibenclamide (GB), GM and gliclazide (GZ), in human plasma.

\section{Experimental}

\section{Chemicals and reagents}

GB active pharmaceutical ingredient (API), 99.50\% of purity, from Cadila Pharmaceuticals (Ahmedabad, Gujarat, India) was donated by Fundação Ezequiel Dias - FUNED (Belo Horizonte, Brazil). GZ API, 99.10\% of purity, from Shandong Keyuas Pharmaceutical (Jinan, Shandong, China) and GM API, $99.96 \%$ of purity, from Mantena Laboratories (Naldonga, Dist, Andhra Pradesh, India) were donated by Cifarma (Belo Horizonte, Brazil). Flufenamic acid (FA), used as internal standard, was from Sigma-Aldrich (Steinheim, Germany) (Figure 2). Acetonitrile Panreac (Barcelona, Spain) and methanol Sigma-Aldrich (Steinheim, Germany) were of HPLC grade. Other analytical solvents and reagents were: acetic acid and monobasic potassium phosphate Sigma-Aldrich (Steinheim, Germany), orthophosporic acid Merck (Darmstadt, Germany) and sodium hydroxide Quimex (São Paulo, Brazil).

\section{Equipment and materials}

Chromatography was performed in a Shimadzu (Kyoto, Japan) system composed by a SCL-10A VP controller, two LC-10AD VP pumps, a CTO-10A VP oven, a SIL-10AD VP automated injector, a SPD-M10A VP diode array detector (DAD), and a Cheminert six port valve (VICI Brockville, Canada). A Poroshell 120 EC-C18 (100 x 4.6 $\mathrm{mm}, 2.7 \mu \mathrm{m})$ fused core column from Agilent Technologies (Santa Clara, USA) and a C18 pre-column (4.0 mm x 3.0 $\mathrm{mm}$ ) from Phenomenex (Torrance, USA) were used for separation. Extraction was performed in a RAM Merck Lichrospher C18 ADS (25 x $4.0 \mathrm{~mm}, 25 \mu \mathrm{m})$ column (Darmstadt, Germany).

\section{Biological sample}

The human plasma samples, obtained by donation from healthy volunteers, were collected in the Laboratório de Hematologia Clínica from Faculty of Pharmacy - Federal University of Minas Gerais. The study was approved by the ethical committee (CAAE number 01892012.0.0000.5149). The blood collection was performed in the morning, with the volunteers fasted or having a light breakfast, characterized by low calorie food and without coffee and chocolate. 
Heparin tubes were used for collection. The blood samples were centrifuged at $480 \mathrm{x} \mathrm{g}$ for 10 minutes at $4{ }^{\circ} \mathrm{C}$ and the obtained supernatant (plasma) was separated and stored at $70{ }^{\circ} \mathrm{C}$ until its use.

\section{Preparation of chemicals solutions}

Stock solutions of GB, GM and GZ at $0.5 \mathrm{mg} \mathrm{mL}^{-1}$ in a mixture of acetonitrile and water $4: 1(\mathrm{v} / \mathrm{v})$ were individually prepared. Work solutions were prepared diluting $1 \mathrm{~mL}$ of each stock solution in acetonitrile and water 50:50 (v/v). The final concentration was $100 \mu \mathrm{g} \mathrm{mL}^{-1}$. Internal standard work solution was prepared at $0.1 \mathrm{mg} \mathrm{mL}^{-1}$ in methanol..

\section{Spiked plasma samples}

After thawing, the plasma samples were centrifuged at $10410 \times g$ for five minutes, spiked with the work solutions and, then, vortexed for 30 seconds in $2200 \mathrm{rpm}$. The final concentration was $5 \mu \mathrm{g} \mathrm{mL} \mathrm{m}^{-1}$.

\section{Evaluation of protein exclusion by RAM-ADS column}

First, different volumes of blank human plasma (20, 50, 100, 200 and $500 \mu \mathrm{L}$ ) were injected in a chromatographic system without the analytical and RAM columns. Water as mobile phase at $1 \mathrm{~mL} \mathrm{~min}{ }^{-1}$ and UV detection at $280 \mathrm{~nm}$ were used. Afterwards, the RAM-ADS column was added to the chromatographic system, still without the analytical column, and the same volumes of blank human plasma were injected. By comparing the peak's areas from the two configurations described above, the protein exclusion percentage of the RAM column for the tested volumes was established.

\section{Optimization of instrumental parameters and chromatographic conditions}

First, the UV-visible spectra (from 190 to $800 \mathrm{~nm}$ ) of the sulfonylureas and of the internal standard at $0.1 \mathrm{mg} \mathrm{mL}^{-1}$ were obtained. Next, the time needed to EMP exclude the proteins from plasma samples was established by analyzing the chromatograms obtained during the evaluation of the protein exclusion by the RAM-ADS column. At this moment, the valve was at position A. After complete exclusion of plasma proteins, the valve was switched to position $\mathrm{B}$, when the AMP ran through the RAM-ADS column eluting the retained analytes. The influence of the valve position (maintaining in the position $\mathrm{B}$ or returning to position A) in the peak area was evaluated. In the case of returning to position $\mathrm{A}$, different switching times (30, 60, 90 and 120 seconds) were tested.

Ultrapure water in different $\mathrm{pH}$ values (4.0, 5.0, 6.0 and 7.0) was tested as EMP. Different compositions of the AMP were tested, using acetonitrile as organic phase and acetic acid $1 \%$ or $10 \mathrm{mM}$ potassium phosphate buffer as aqueous phase, both with $\mathrm{pH} 3.0$ ). Also, different proportions and flow-rates were evaluated, as long as the elution mode: isocratic or gradient. After that, different sample volumes $(20,50,100,200$ and $500 \mu \mathrm{L})$ were injected, in order to evaluate the effect on the method detectability.
In order to establish the more appropriate column-switching configuration for the simultaneous analysis of the three sulfonlyureas, backflush and foreflush were assessed (Figure 1).

\section{Protein precipitation}

The effect of a previous PP on the analyte's peak area was tested. The analyte's peak area obtained with PP, RAMADS, both alone, and with the combination of RAM and PP were compared. For PP, acetonitrile was added to the spiked plasma in the proportion of $1: 1(\mathrm{v} / \mathrm{v})(25)$ followed by vortex for 1 minute and centrifugation at $10410 \times \mathrm{x}$ during 5 minutes. Then, the supernatant was collected and filtered in regenerated cellulose membrane filter $(0.45 \mu \mathrm{m})$.

\section{Results and discussion}

\section{Evaluation of protein exclusion by RAM-ADS column}

After the analysis of blank plasma samples using the chromatographic system without (representing the concentration of $100 \%$ of plasma proteins), and with (representing plasma proteins excluded) the RAM-ADS column, plasma protein exclusion percentage by RAM-ADS column, for each volume injected, was calculated (Table 1). The values obtained were considered satisfactory, since it was higher than $100 \%$ for all tested volumes. The mean was $104.5 \%$, with a relative standard deviation of only $2.15 \%$, indicating total exclusion of plasma proteins by the RAMADS column in less than 2 minutes (Figure 3).

Table 1 - Plasma protein exclusion percentages by the RAM-ADS column.

\begin{tabular}{|c|c|c|c|c|}
\hline \multirow{2}{*}{$\begin{array}{l}\text { Injection } \\
(\mu \mathrm{L})\end{array}$} & \multirow{2}{*}{ volume } & \multicolumn{2}{|c|}{ Peak area } & \multirow{2}{*}{$\begin{array}{l}\text { Exclusion } \\
(\%)\end{array}$} \\
\hline & & $\begin{array}{l}\text { Without } \\
\text { RAM }\end{array}$ & With RAM & \\
\hline 20 & & 20509651 & 20674455 & 100.8 \\
\hline 50 & & 32340063 & 34123606 & 105.5 \\
\hline 100 & & 45236230 & 48327986 & 106.8 \\
\hline 200 & & 49928515 & 52410799 & 104.9 \\
\hline 500 & & 50935121 & 53198585 & 104.4 \\
\hline Mean & & & & $104.5 \%$ \\
\hline$R S D$ & & & & 2.15 \\
\hline
\end{tabular}




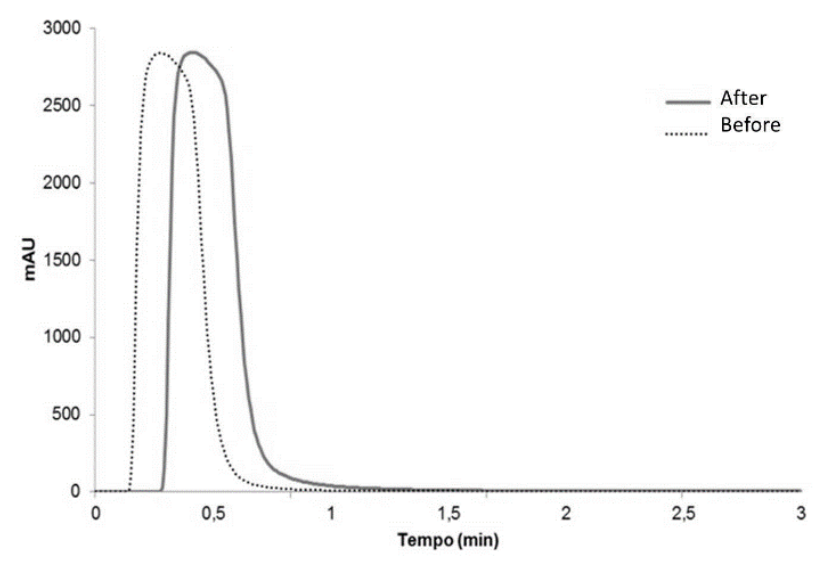

Figure 3. Chromatograms obtained before and after plasma protein exclusion by the RAM-ADS column. Sample volume: 200 /L. Mobile phase: ultrapure water, flow-rate: $1.0 \mathrm{~mL} \mathrm{~min}{ }^{-1}$. Wavelength detection:

nm.

\section{Optimization of instrumental parameters and chromatographic conditions}

In order to choose the internal standard for the bioanalytical method, different compounds available in our study group, with similar physical-chemical properties, retention time and maximum absorption wavelengths as the sulfonylureas, were evaluated. Considering these requirements, FA ( $\log P$ of 5.25 and $\mathrm{pKa}$ of 3.88) was chosen as the internal standard. A maximum absorption at $230 \mathrm{~nm}$ was observed for the sulfonylureas and FA, when solutions at $0.1 \mathrm{mg} \mathrm{mL}^{-1}$ in methanol were tested from 190 to $800 \mathrm{~nm}$. Therefore, 230 $\mathrm{nm}$ was chosen for the chromatographic method.

As can be observed in Figure 3, after 3 minutes $100 \%$ of plasma proteins were excluded from the RAM-ADS column for all volumes tested. Therefore, at 3 minutes after injection the valve was switched from position A to position $B$.

The chromatograms of blank and spiked plasma, without returning the valve to the initial position (position $\mathrm{A}$ ) are presented in Figure 4. The interference of the blank plasma in the peaks of the analytes makes their integration inappropriate. Thus, the returning of the valve from position B to position A was necessary. Different time intervals (30, 60, 90 and 120 seconds) were tested. At 90 and 120 seconds, the determination of GZ peak area was not possible due to a co-elution with a plasma interference. Therefore, 60 seconds was selected, since there was an increase in the peak area for all the analytes and the internal standard when compared to 30 seconds (Figure 5)

Ultrapure water, a weak solvent in reversed phase, was used as EMP because of its low affinity for the analytes and IS, assuring a high interaction of these analytes with the RAMADS column. Besides that, water has the ability to ionize the sample proteins favoring their exclusion by electrostatic repulsion inside the RAM-ADS column. Aiming to evaluate the elimination of the proteins, four values of $\mathrm{pH}$ were evaluated: 4.0, 5.0, 6.0 and 7.0. When neutral $\mathrm{pH}$ was used, a lack of resolution between the chromatographic peaks was observed. At $\mathrm{pH} 4.0$, a residual effect related to the IS was observed in the chromatogram of blank plasma obtained after the analysis of spiked plasma. Since this phenomenon was not observed in $\mathrm{pH} 5.0$ and 6.0, this range was employed.

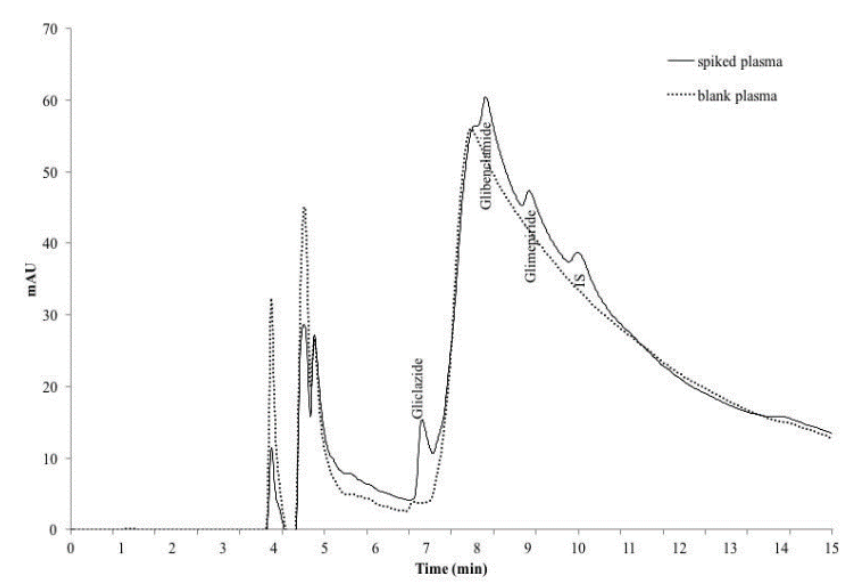

Figure 4. Chromatograms obtained for the analysis of spiked and blank plasma, without returning the valve from position B to A. Sample volume: 200 (L. EMP: ultrapure water, flow-rate: $1.0 \mathrm{~mL}$ $\min ^{-1}$. AMP: acetonitrile and $10 \mathrm{mM}$ phosphate buffer $\mathrm{pH} 3.0$

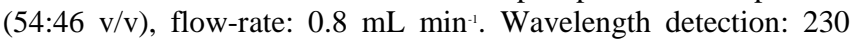
nm.

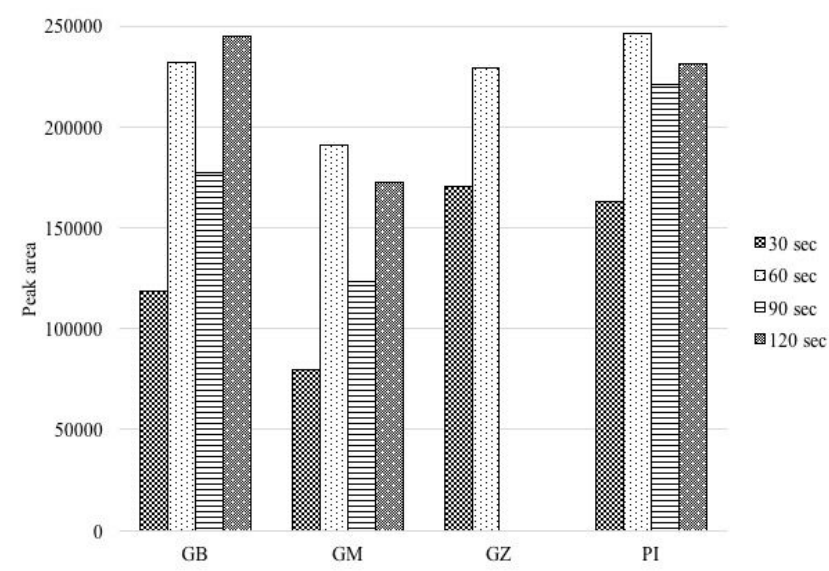

Figure 5. Peak areas of GB, GM, GZ and IS in different time intervals, after which the valve was switched from position B to position A.

Different AMP compositions were tested using acetonitrile (organic phase) and acetic acid $1 \%$ or $10 \mathrm{mM}$ phosphate buffer, both at $\mathrm{pH} 3.0$ (aqueous phase), varying the proportion of the phases, flow-rate and elution mode (gradient or isocratic). In view of the obtained results in terms of resolution and baseline noise, AMP was composed by acetonitrile and $10 \mathrm{mM}$ phosphate buffer $\mathrm{pH} 3.0$, in isocratic mode $(54: 46 \mathrm{v} / \mathrm{v})$, in a flow-rate of $0.8 \mathrm{~mL} \mathrm{~min}^{-1}$. Different sample volumes of human plasma were evaluated. As can be observed in Table 2, there was an improvement in the chromatographic peak areas and heights when the injection volumes were increased. An exception was a decreasing in peak areas and heights when the volume changed from 200 to $500 \mu \mathrm{L}$ of plasma. A possible reason is the saturation of the RAM column, reducing its capacity to adsorb the analytes. Due to the decrease in peak area and height when $500 \mu \mathrm{L}$ of the sample was injected in the 
chromatographic system, $200 \mu \mathrm{L}$ was defined as the injection volume, since there was an increase in the peaks when compared to the injection of $100 \mu \mathrm{L}$ of plasma, improving the method detectability. It is important to note that during this step of the method development, blank plasma samples were injected between spiked samples analysis and no carry-over effect was observed.

Table 2 - Variation of peaks areas and heights as a function of the volume of injected plasma $(\mu \mathrm{L})$.

\begin{tabular}{|c|c|c|c|c|c|}
\hline & & $20 \rightarrow 50(\%)$ & $50 \rightarrow 100(\%)$ & $100 \rightarrow 200(\%)$ & $200 \rightarrow 500(\%)$ \\
\hline \multirow{5}{*}{ Area } & GZ & 133.1 & 95.9 & 18.1 & -3.8 \\
\hline & GB & 89.4 & 226.0 & 7.3 & -5.5 \\
\hline & GM & 200.1 & 313.1 & 4.4 & -8.4 \\
\hline & IS & 88.0 & 173.3 & 2.8 & -2.6 \\
\hline & Mean & 127.6 & 202.1 & 8.2 & -5.1 \\
\hline \multirow{5}{*}{ Height } & GZ & 133.5 & 96.2 & 7.1 & -2.9 \\
\hline & GB & 116.6 & 232.2 & 3.6 & -4.9 \\
\hline & GM & 228.2 & 315.5 & 2.9 & -8.3 \\
\hline & IS & 137.6 & 197.3 & 2.8 & -2.2 \\
\hline & Mean & 154.0 & 210.3 & 4.1 & -4.6 \\
\hline
\end{tabular}

After the optimization of the chromatographic conditions, backflush and foreflush modes were compared for the simultaneous determination of GB, GM and GZ. In foreflush configuration a baseline noise was observed, which compromised the appropriate peak integration. Moreover, the resolution between the sulfonylureas was poor. A possible reason is the flow direction of the AMP, which is the same of the EMP. Therefore, the analytes eluted through the whole length of the RAM column before achieve the analytical column. This might lead to the adsorption of the analytes along the RAM column, resulting in peak broadening.

On the other hand, in backflush mode, the flow direction of the AMP is opposite to the EMP. Therefore, the analytes adsorbed in the head of the RAM column were eluted directly into the analytical column, going through a small pathway resulting in less extra column volume and avoiding peak broadening. In view of the obtained results and the small amount of time spent in the analysis of the studied sulfonylureas, only 12 minutes, backflush was the selected column-switching configuration.

\section{Protein precipitation}

When PP was used as a single technique, the peak area for all analytes increased with higher injected plasma volumes. This gain was much more pronounced when the volume was $100 \mu \mathrm{L}$ (Figure 6). Possibly, the increase would be higher with 200 and $500 \mu \mathrm{L}$; however, it was not possible to identify the compound's peaks due to baseline noise and poor resolution between the analytes. As can be observed, the peak areas were higher for PP when compared with RAM-ADS and RAM-ADS + PP. A possible reason is the disruption of drug-protein binding by the organic solvent, improving analytes recovery.

Despite the higher peak areas observed with PP, it was not considered for the analysis of the studied sulfonylureas, in view of the increased analysis time, chance of errors, and analyst exposure, since it is a non-automated technique.

The peak areas obtained with RAM-ADS column were similar to those obtained with the combination of both techniques (PP + RAM), another indication of a possible saturation of the RAM column. Therefore, the RAM column was maintained as the only sample treatment technique, since its combination with PP did not add any improvement. Figure 7 shows the chromatogram of blank and spiked plasma samples obtained with the optimized method. 

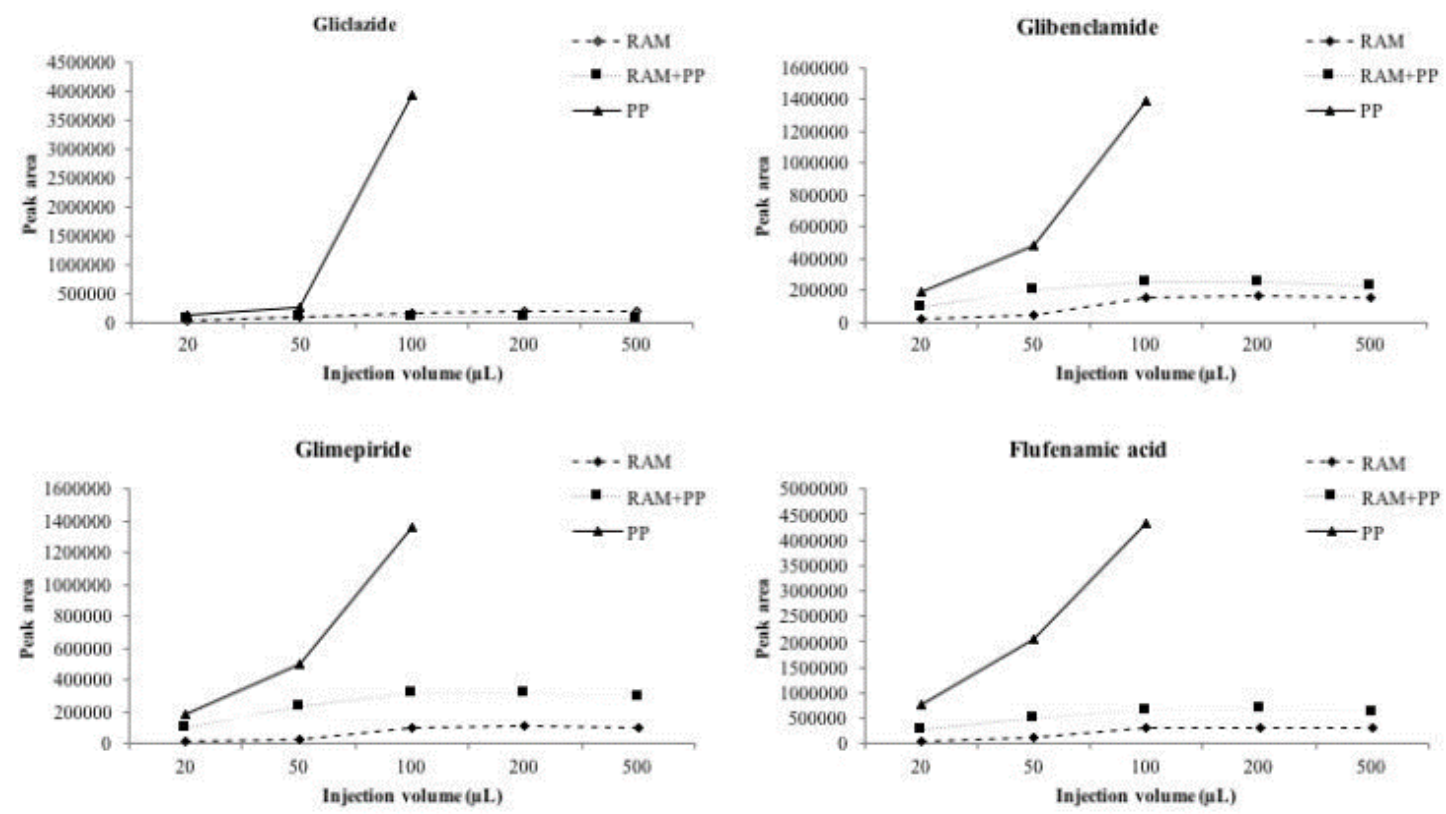

Figure 6. Peak areas of GB, GM, GZ and IS as a function of the sample treatment technique and of the volume of injected plasma ( $\mu \mathrm{L})$.

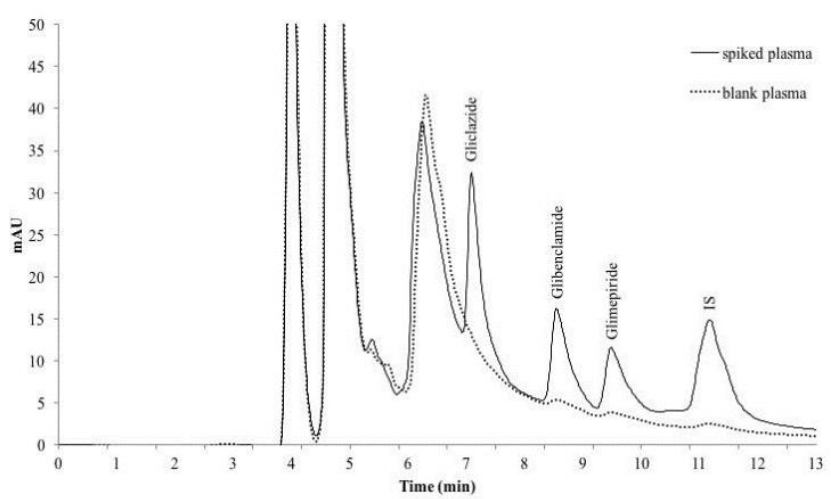

Figure 7. Chromatograms obtained after the injection of spiked plasma followed by blank plasma using the optimized method. Sample volume: $200 \mu \mathrm{L}$. EMP: ultrapure water, $\mathrm{pH}$ : 6.0; flow: 1.0 $\mathrm{mL}$ min-1. AMP: acetonitrile and phosphate buffer $10 \mathrm{mM} \mathrm{pH} 3.0$ (54:46), flow: $0.8 \mathrm{~mL}$ min-1. Wavelength: $230 \mathrm{~nm}$.

\section{Conclusion}

The column-switching system using the backflush configuration, which employed a six-port valve, allowed the use of two dimensions in the chromatographic system, one for sample treatment and the other for separation. This system allowed the direct injection of human plasma samples in the chromatographic system.

The developed method showed several advantages over those already published in the peer-review literature dealing with sulphonylureas determination: less exposure of the analyst to the biological sample and to the solvents used in the analysis, less chances of errors due to the handling of the samples and reduction of the time spent in the analysis, increasing the productivity and reducing the expense of organic solvents.
The developed method demonstrated to be simple and fast, in addition to allowing simultaneous determination of three sulfonylureas, glibenclamide, glimepiride and gliclazide, in human plasma. The total analysis time, encompassing the chromatographic step ( 8 minutes) and the sample treatment step $(3$ minutes for the protein exclusion and 1 minute for the analytes elution) was only 12 minutes.

\section{Conflict of interest}

The authors declare there is no conflicts of interest.

\section{Acknowledgements}

The authors would like to thank Funed and Cifarma for donating the active pharmaceutical ingredients and CNPq, FAPEMIG and CAPES for the financial support.

\section{References}

1. Queiroz MEC, Lanças FM. Análise de fármacos em material biológico: acoplamento microextração em fase sólida "no tubo" e cromatografia líquida de alta eficiência. Quim. Nova. 2005; 28(5):880-886.

2. Cassiano NM, Lima VV, Oliveira RV, De Pietro AC, Cass QB. Development of restricted-access media supports and their application to the direct analysis of biological fluid samples via high-performance liquid chromatography. Anal. Bioanal. Chem. 2006; 384:14621469. 
3. Mullet WM. Determination of drugs in biological fluids by direct injection of samples for liquidchromatographic analysis. J. Biochem. Biophys. Methods. 2007; 70:263-273.

4. Sadílek P, Satínský D, Solich P. Using restricted-access materials and column switching in high-performance liquid chromatography for direct analysis of biologically-active compounds in complex matrices. Trends Anal. Chem. 2007; 26(5):375-384.

5. Souverain S, Rudaz S, Veuthey JL. Restricted access materials and large particle supports for on-line sample treatment: an attractive approach for biological fluids analysis. J. Chromatogr., B. 2004; 801:141-156.

6. Chen Y, Guo Z, Wang X, Qiu C. Sample treatment. J. Chromatogr., A. 2008; 1184:191-219.

7. Desilets CP, Rounds MA, Regnier FE. Semipermeablesurface reversed-phase media for high-performance liquid chromatography. J. Chromatogr.-, A. 1991; 544:25-39.

8. Bakhtiar R, Majumdar TK. Tracking problems and possible solutions in the quantitative determination of small molecule drugs and metabolites in biological fluids using liquid chromatography-mass spectrometry. J Pharmacol Toxicol Methods. 2007; 55:227-243.

9. Lima VV, Cassiano NM, Cass QB. Desenvolvimento de colunas cromatográficas de meios de acesso restrito proteína imobilizada e suas avaliações para análise de fármacos com injeção direta de plasma humano. Quim. Nova. 2006; 29(1):72-78.

10. Krishnam TR, Ibraham I. Solid-phase extraction technique for the analysis of biological samples. J. Pharm. Biomed. Anal. 1994; 12(3):287-294.

11. Fagundes VF, Leite CP, Pianetti GA, Fernandes C. Rapid and direct analysis of statins in human plasma by column-switching liquid chromatography with restricted-access material. J. Chromatogr. B. 2014; 947 948:8-16.

12. World Health Organization. [citad 2015 Jun 17]. Available from: http://www.who.int/en/.

13. Goodman LS, Gilman A. As Bases Farmacológicas da Terapêutica. 12 ed. Rio de Janeiro: Mcgraw-Hill; 2012.

14. Ramalho ACR, Lima ML. Insulina e Antidiabéticos Orais. In: Silva P, editor. Farmacologia. 7ed. Rio de Janeiro: Guanabara Koogan; 2006. p. 805-823.

15. Moreau RLM, Siqueira MEPB. Toxicologia Analítica. $1^{\mathrm{a}}$ ed. Rio de Janeiro: Guanabara Koogan; 2008.

16. Polagani SR, Pilli NR, Gajula R, Gandu V. Simultaneous determination of atorvastatin, metformin and glimepiride in human plasma by LC-MS/MS and its application to a human pharmacokinetic study. J. Pharm. Anal. 2013; 3(1): 9-19.

17. El-Enany NM, Abdelal AA, Belal FF, Itoh YI, Nakamura MN. Development and validation of a repharsed phase-HPLC method for simultaneous determination of rosiglitazone and glimepiride in combined dosage forms and human plasma. Chem Cent J. 2012; 6(9):1-10.

18. Sultana N, Arayne MS, Iftikhar B. Simultaneous determination of atenolol, rosuvastatin, spironolactone, glibenclamide and naproxen sodium in pharmaceutical formulations and human plasma by RP-HPLC. J. Chin. Chem. Soc. 2008; 55:1022-1029.

19. Chakradhar L, Kallem R, Karthik A, Sundari BT, Ramesh S, Mullangi R, et al. A rapid and highly sensitive method for the determination of glimepiride in human plasma by liquid chromatography-electrospray ionization tandem mass spectrometry: application to a pre-clinical pharmacokinetic study. Biomed. Chromatogr. 2008; 22:58-63.

20. Yuzuak N, Ozden T, Eren S, Ozilhan S. Determination of glimepiride in human plasma by LC-MS-MS. Chromatographia. 2007; 66:165-168.

21. Gedeon C, Kapur B, Aleksa K, Koren G. A simple and rapid HPLC method for the detection of glyburide in plasma original research communication (analytical). Clin. Biochem. 2008; 41:167-173.

22. Souza KC, Andrade GF, Vasconcelos I, Viana IMO, Fernandes C, Souza EMB. Magnetic solid-phase extraction based on mesoporous silica-coated magnetic nanoparticles for analysis of oral antidiabetic drugs in human plasma. Mater. Sci. Eng., C. 2014; 40:275-280.

23. Viana IMO, Lima PPR, Soares CDV, Fernandes C. Simultaneous determination of oral antidiabetic drugs in human plasma using microextraction by packed sorbent and high-performance liquid chromatography. J. Pharm. Biomed. Anal. 2014; 96:241-248.

24. Song Y, Maeng J, Hwang H, Park J, Kim B, Kim J, et al. Determination of glimepiride in human plasma using semi-microbore high performance liquid chromatography with column-switching. J. Chromatogr., B. 2004; 810:143-149.

25. Polson C, Sarkar P, Incledon B, Raguvaran V, Grant R. Optimization of protein precipitation based upon effectiveness of protein removal and ionization effect in liquid chromatography-tandem mass spectrometry. J. Chomatogr. B. 2003; 785:263-275. 